\title{
The Staff Meeting as a Departmental Seminar
}

Julian S. Fowler is librarian of the Oberlin College Library, Oberlin, Ohio.

N ANY plan for improving the subject or I the functional organization of our libraries, the intellectual development of the staff is more than implied. It becomes mandatory. No royal road to this learning has been completely determined, in spite of the fact that for some years the professional journals have devoted no small amount of space to the subject. Its very nomenclature is still undefined.

A college library cannot function as it should without a well-balanced subject collection handled by a staff acquainted with the content and the possibilities of that collection. Equally important is the ability of the staff to help build up and keep up the collection, to make it well rounded, to know the best literature in different fields so that they can not only supply, but even anticipate, the needs of their public.

No one can dispute that to fulfil this obligation some kind of post-professional or continuing education is necessary. The question is, what form shall it take? Should it mean undergraduate college work for such of the staff as lack it and show promise and interest in advancement? Should it mean professional training for those who have college degrees? Should it mean graduate study for those who have both the bachelor's degree in arts and in library science? It means any or all of these, according to circumstances. Professional training is obviously one very necessary part of our intellectual development, but it is not available in the average arts college. Our problem at the moment is to find ways of applying, to the enrichment of library service, the academic training which is right at hand.

A college library has a particularly strategic position for this kind of continuing education for the staff. Its members can, if they choose, meet the requirements for a master's degree without a large monetary investment though not without an extra physical and mental load which must be reckoned with. If leaves cannot be arranged, service on a half-time basis might be. It should not be difficult to plan a rotation of study programs for a selected group so that the work of the library would not be affected.

The study program should be concentrated in a small, carefully selected group, because its adoption would be in most places an experiment which must prove both to college and library administration that there will be not even a temporary decrease in the library's efficiency. Careful planning should distribute both the load and the benefits to different intellectual fields as well as to different departments of the library.

There follows at once the question of how these benefits can be coordinated so that they are shared not only by those participating, but also by the other mem- 
bers of the staff. In other words, can the formal study of this selected group be made the leaven for a general intellectual stimulation?

The staff meeting has usually been a forum for the discussion of administrative problems of one sort or another. Could it not be made a part of a staff educational program? I must admit my own inadequate knowledge of the working details of such an application and ask you to consider the possibilities of it as they have come to me from others (see list of references), and to help me test the propriety of my own ideas.

\section{Tentative Suggestions for Staff Seminar Study}

It is my purpose to put before you for discussion some tentative and perhaps wholly impractical suggestions by which the study of staff members might be used to benefit the general group. There would not be one general staff seminar, but a number, each under the leadership of a staff member engaged in active study. Let us suppose that three are thus engaged. Staff members could elect membership in any one of the groups. Such membership might or might not be granted, according to ability, background, and proved capacity (or lack of it) for real work. Some such standard is, I feel sure, necessary to eliminate those who would contribute nothing and who would gain nothing but a leisure hour now and then.

Local conditions must determine the method of conducting seminars, their frequency, and the period over which they would be distributed. One hesitates to do more than generalize about the method. Obviously it must be adapted to the subject, the intensity of study desired, and the enthusiasm of the members. Whenever possible, there should be discussion which the leader would direct rather than dominate. It has been suggested that if the leaders are themselves students of a new subject, meetings should not begin until the second semester when fundamentals had already been mastered. Eight fortnightly sessions would divide the period fairly well. If the leader and perhaps the members of the group are already acquainted with the field, the seminar might follow closely the work presented in the classroom and be distributed over the full year with a greater attention to subject matter and bibliographical material.

Ann Messick's accounts of her experiment at the Colorado State College of Agriculture (see references) might sum up equally well the advantages and disadvantages of any other. The first she terms manifold, the latter surmountable.

In venturing a little farther than $M$ iss Messick into an uncharted territory, I may have ventured too far. Perhaps the chances for the success or failure of a staff-conducted seminar rest too heavily on the personality and ability of the leader. Perhaps I have assumed too much on behalf of the rest of the staff. Certainly it all means work, and plenty of it. Is the experiment worth while? To put the challenge bluntly-have we got what it takes?

\section{References}

Fay, Lucy. "Continuing Education of the College Library Staff." Library Journal 62:199-20I, Mar. I, I937.

Hurt, Peyton. "Staff Specialization." A.L.A. Bulletin 29:417-2I, July 1935.

Messick, Ann. "Library Staff Seminar." Library Journal 63:I 7I, Mar. I, I938. -. "Staff Reading." Library Journal 61 :709, Oct. I, I936.

. "Planned Reading of the Library Staff." A.L.A. Bulletin 31 : 753-54, Oct. 15, 1937 . 